\title{
Haemodynamic Effects of Ethyl Alcohol in Patients with Coronary Heart Disease
}

\author{
NEVILLE CONWAY*
}

\author{
From The National Heart Hospital, London W.1
}

The place of ethyl alcohol (alcohol) in the management of patients with coronary heart disease has received much attention in the past. It relieves or prevents angina in many instances, but Russek, Naegele, and Regan (1950) and Russek, Zohman, and Dorset (1955) have shown that the exercise electrocardiogram is not improved and the benefit of alcohol has been attributed to its psychological effect. In these and similar studies little attention has been paid to the dose of alcohol, its rate of absorption, and the blood levels attained. Several haemodynamic studies of the action of alcohol exist. With a few exceptions they have been carried out on healthy anaesthetized dogs or heart-lung preparations and, though detailed, the results are often conflicting. Thus coronary sinus flow has been shown to rise (Lasker, Sherrod, and Killam, 1955; Ganz, 1963) or fall (Degerli and Webb, 1963; Leighninger, Rueger, and Beck, 1961). Cardiac output probably declines though again there is no unanimity (Degerli and Webb, 1963). A fall in arterial pressure may occur (Willard and Horvath, 1964); and Moss, Chenault, and Gaston (1959) have demonstrated unusual vulnerability to surgical shock, but in the main little change has been noted. In many cases alcohol has been given intravenously and by this route high blood levels are quickly reached, even with moderate dosage.

Clearly, the application of the findings of such experiments to patients with heart disease must be cautious. The present study, therefore, examines the haemodynamic consequences of a drink of alcohol in patients with coronary heart disease and includes observations on blood alcohol concentrations.

\section{SUBJECTS AND MethodS}

Eight male patients were studied, aged between 46 and 63 years (mean 57). All had a history of angina of effort

Received October 26, 1967.

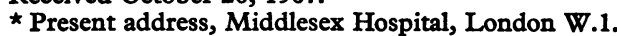

due to coronary heart disease (duration 1-10 years, mean 4.6 years). Three had had a myocardial infarction several years previously. One was hypertensive and two had atrial fibrillation. In each case no recent alteration in the pattern of angina had occurred and none of them had symptoms or any of the signs of heart failure. The electrocardiogram was normal in one case only, the rest showing evidence of ischaemia. Two had intermittent claudication, the others being free of signs of peripheral vascular disease. All were accustomed to alcohol in moderation only.

The study was carried out in the afternoon, lunch being omitted to promote alcohol absorption. No alcohol was taken for 24 hours beforehand. A fine $130 \mathrm{~cm}$. polythene catheter (FG3 Portland Plastics) was flow guided from a forearm vein to the pulmonary artery under pressure control. A brachial artery catheter (TF 30) was inserted by the Seldinger technique. Pressures were measured using a Consolidated Electrodynamics strain gauge type 4-326-L212 and a Sanborn direct writing recorder. Zero levels were the mid-chest position (supine) and the insertion of the 4th rib into the sternum (erect). Cardiac outputs were estimated by the indicator dilution method using indocyanine green injected into the pulmonary artery and sampled at the brachial artery by a Norman N.E.P. constant withdrawal pump through the Gilford cuvette. The oxygen content of the blood was measured by the Kipp haemoreflector. Pulse rate was obtained from the electrocardiogram. Resting electrocardiograms were standard 12-lead tracings, but during exercise a modified CR5 lead was used with the remote lead on the right shoulder, thus permitting free leg movement. Blood alcohol levels were estimated by the micro-diffusion method of Conway (1957). Urine volume was measured over the entire period of study in 6 subjects. Left ventricular work was calculated as the product of cardiac output and the mean arterial ejection pressure, and tension time index as the product of the heart rate, the mean arterial ejection pressure, and the ejection time measured from the arterial pressure trace. Peripheral vascular resistance was calculated from the cardiac output and mean arterial pressure. Exercise was carried out in the sitting position on an Elema Schönander bicycle ergometer 638 
vations were made in the supine position at 15 -minute intervals to establish a basal state. They were repeated once at rest in the erect position seated on the bicycle ergometer, and then at three consecutive work loads150, 250, and $350 \mathrm{kp} . \mathrm{m}$. Exercise at each level was continued for 4 minutes when a steady state was assumed and observations were started. (Mean periods of exercise at each work load were $6 \cdot 2,5 \cdot 3$, and 6.7 minutes, respectively.) After a period of rest in the supine position (20-30 minutes) further observations were made. The patient then drank, within 2 minutes, $0.5 \mathrm{~g}$. $/ \mathrm{kg}$. body weight of pure ethyl alcohol diluted by its own volume of water and flavoured with fruit juice. This is roughly equivalent in a $70-80 \mathrm{~kg}$. man to $3-4$ whiskies. After rapid ingestion of this quantity of alcohol blood levels may be expected to climb for 45-60 minutes, after which a "plateau" will occur followed by a gradual decline (C. S. Beck and N. Conway, unpublished observations). Blood alcohol concentrations were estimated with each succeeding group of observations including each exercise level. After alcohol three resting measurements (supine) were repeated at approximately 15-minute intervals (means 18, 32, and 44 minutes) and after a further 15 minutes, exercise was repeated exactly as before with preliminary observations at rest seated on the ergometer (mean periods of exercise at each load $5 \cdot 8,5 \cdot 4$, and 6.7 minutes, respectively).

\section{RESULTS}

\section{(A) Blood Alcohol Concentrations}

These are shown in Fig. 1, mean values being given in Tables I and II. Individual alcohol absorption was variable but this is not unusual. Fig. 1 compares the blood alcohol curves of these patients with the findings in 13 healthy male medical students given comparable quantities of alcohol in the same way (C. S. Beck and N. Conway, unpublished observations), and similar variation is evident. During the exercise period blood alcohol values remained relatively constant for each subject.

\section{(B) At Rest}

Haemodynamic results. These are given in Table I. Control values in the first period of rest are included for the sake of completeness but are not employed for comparison purposes, results after alcohol being compared with the last set of resting observations before its ingestion. After alcohol, systolic arterial pressure fell, the drop becoming significant at 30 minutes. Diastolic pressures also dropped but statistical significance was not achieved. Cardiac output, left ventricular work, and tension time index all declined significantly from 30 minutes onwards. Heart rate, peripheral resistance, and arteriovenous oxygen difference showed no alteration. Stroke volume and pulmonary artery mean pressure fell but not significantly so. The principal changes increased with
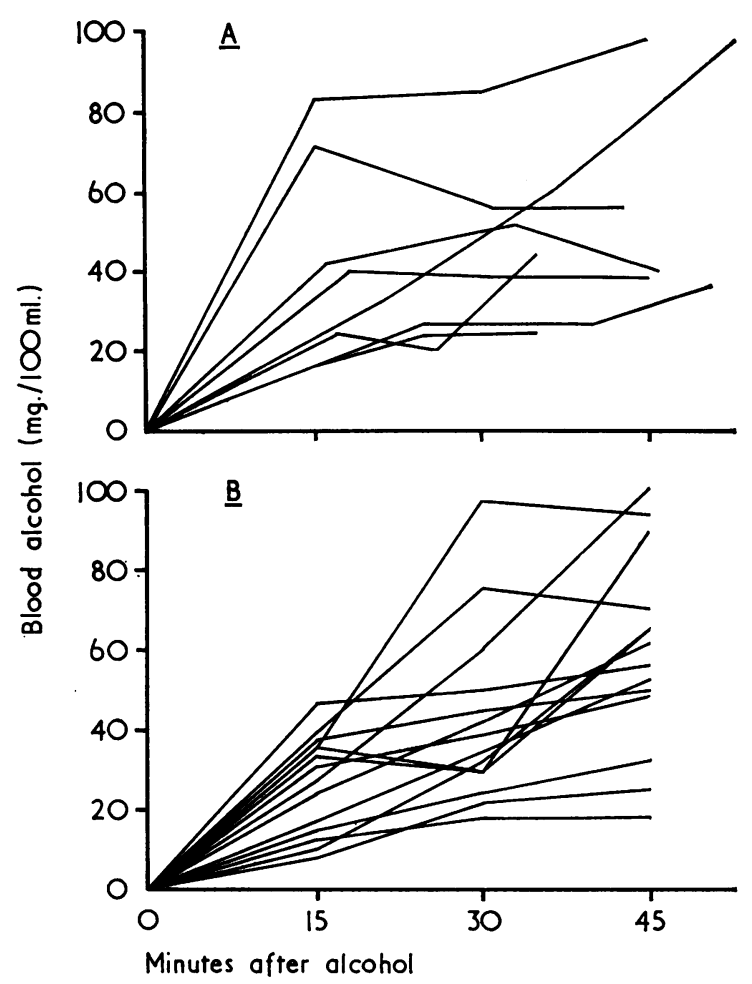

FIG. 1.-Alcohol absorption curves. (A) Present study (alcohol given $28-41 \mathrm{~g}$., mean $35 \mathrm{~g}$.); (B) 13 healthy male medical students each given $40 \mathrm{~g}$. alcohol.

rising blood alcohol and reached a maximum 45 minutes after alcohol (Fig. 2 and 3).

Electrocardiograms. After alcohol, flattening of $\mathrm{T}$ waves was seen in V4-V6 in two subjects (E.B., Fig. 4; and T.R.) and S-T depression in another (A.C., Fig. 4). No other unequivocal change occurred.

Angina. This did not occur at rest.

\section{(C) Exercise}

Haemodynamic results. These are given in Table II. Each work load is compared before and after alcohol. Resting erect values are not compared. The principal changes were a significant reduction in arterial pressure (both systolic and diastolic) at each work load. Cardiac output and stroke volume were lower but only at $150 \mathrm{kp} . \mathrm{m}$. were these changes significant (Fig. 5). Heart rates were identical and arteriovenous oxygen difference unaffected. Pulmonary artery mean pressure was 
TABLE I

MEAN VALUES AT REST (SUPINE)

\begin{tabular}{|c|c|c|c|c|c|c|c|}
\hline & \multirow{2}{*}{\multicolumn{3}{|c|}{$\begin{array}{l}\text { Basal readings before first } \\
\text { exercise run }\end{array}$}} & \multirow{2}{*}{$\begin{array}{l}\text { Before } \\
\text { alcohol }\end{array}$} & \multicolumn{3}{|c|}{ After alcohol (min.) } \\
\hline & & & & & 18 & 32 & 44 \\
\hline 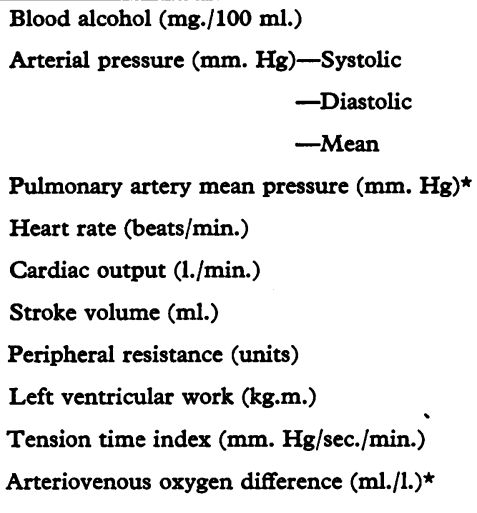 & $\begin{array}{l}- \\
154 \\
(24) \\
81 \\
(10) \\
109 \\
(12) \\
18 \\
(6) \\
75 \\
(16) \\
4 \cdot 6 \\
(1 \cdot 0) \\
63 \\
(19) \\
24 \\
(4) \\
8 \cdot 4 \\
(2 \cdot 6) \\
2860 \\
(640) \\
71 \\
(12)\end{array}$ & $\begin{array}{l}- \\
150 \\
(25) \\
79 \\
(10) \\
108 \\
(11) \\
19 \\
(6) \\
73 \\
(16) \\
4 \cdot 6 \\
(0 \cdot 9) \\
65 \\
(19) \\
24 \\
(5) \\
8 \cdot 2 \\
(2 \cdot 7) \\
2740 \\
(520) \\
\end{array}$ & $\begin{array}{c}- \\
151 \\
(19) \\
80 \\
(9) \\
107 \\
(10) \\
18 \\
(5) \\
74 \\
(16) \\
4 \cdot 7 \\
(0 \cdot 9) \\
66 \\
(20) \\
22 \\
(4) \\
8 \cdot 1 \\
(2 \cdot 3) \\
2690 \\
(450)\end{array}$ & $\begin{array}{c}- \\
139 \\
(16) \\
76 \\
(8) \\
100 \\
(11) \\
17 \\
(5) \\
83 \\
(13) \\
4 \cdot 8 \\
(0 \cdot 9) \\
60 \\
(17) \\
21 \\
(5) \\
7 \cdot 9 \\
(1 \cdot 9) \\
2660 \\
(490) \\
67 \\
(11)\end{array}$ & $\begin{array}{c}42 \\
(22) \\
132 \\
(15) \\
75 \\
(8) \\
98 \\
(11) \\
18 \\
(5) \\
80 \\
(8) \\
4 \cdot 4 \\
(1 \cdot 1) \\
55 \\
(13) \\
23 \\
(5) \\
7 \cdot 0 \\
(2.5) \\
2380 \\
(550)\end{array}$ & $\begin{array}{c}45 \\
(21) \\
127 \dagger \\
(18) \\
71 \\
(10) \\
91 \dagger \\
(14) \\
16 \\
(3) \\
78 \\
(10) \\
4 \cdot 3 \dagger \\
(1 \cdot 1) \\
57 \\
(18) \\
22 \\
(4) \\
6 \cdot 6 \dagger \\
(2 \cdot 3) \\
2260 \dagger \\
(510) \\
65 \\
(7)\end{array}$ & $\begin{array}{c}54 \\
(26) \\
122 \dagger \\
(19) \\
69 \\
(10) \\
88 \dagger \\
(14) \\
15 \\
(4) \\
78 \\
(11) \\
4 \cdot 2 \dagger \\
(0 \cdot 8) \\
55 \\
(13) \\
22 \\
(4) \\
6 \cdot 1 \dagger \\
(1.7) \\
2140 \dagger \\
(380) \\
-\end{array}$ \\
\hline
\end{tabular}

Standard deviations in parentheses.

$\star$ Seven patients only.
+ Statistically significant change $(p=$ or $<0.05)$, using Student's $t$ test to determine the significance of the observed difference from zero.

lower at each exercise level, significantly so at 250 and 350 kp.m. Left ventricular work (Fig. 6) and tension time index were much reduced at each exercise level.

Electrocardiograms. After alcohol, resting CR5 showed $T$ wave inversion in one subject (T.R.), a change persisting during exercise (Fig. 7). Another
(P.G.) showed a positive exercise test with S-T depression for the first time after alcohol, work loads being comparable. A third (L.W.) had greater S-T depression. No difference in the exercise changes was observed in the others.

Angina. This occurred in 5 patients. Table III gives the total amount of work done until the point

TABLE II

MEAN VALUES AT REST (ERECT) AND ON EXERCISE BEFORE AND AFTER ALCOHOL

\begin{tabular}{|c|c|c|c|c|c|c|c|c|}
\hline & \multicolumn{4}{|c|}{ Before alcohol } & \multicolumn{4}{|c|}{ After alcohol } \\
\hline & \multirow{2}{*}{$\begin{array}{c}\text { Resting } \\
\text { erect }\end{array}$} & \multicolumn{3}{|c|}{ Exercise (kp.m./min.) } & \multirow{2}{*}{$\begin{array}{c}\text { Resting } \\
\text { erect }\end{array}$} & \multicolumn{3}{|c|}{ Exercise (kp.m. $/$ min.) } \\
\hline & & 150 & 250 & 350 & & 150 & 250 & 350 \\
\hline 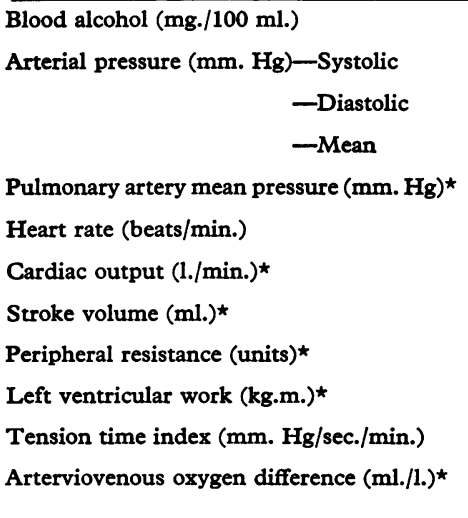 & $\begin{array}{l}- \\
145 \\
(16) \\
80 \\
(6) \\
101 \\
(10) \\
15 \\
(3) \\
79 \\
(13) \\
4 \cdot 0 \\
(0 \cdot 9) \\
54 \\
(15) \\
26 \\
(5) \\
6 \cdot 7 \\
(1 \cdot 6) \\
2540 \\
(460) \\
-\end{array}$ & $\begin{array}{c}- \\
167 \\
(16) \\
83 \\
(6) \\
116 \\
(9) \\
23 \\
(6) \\
101 \\
(10) \\
6 \cdot 9 \\
(1 \cdot 1) \\
71 \\
(15) \\
17 \\
(2) \\
13 \cdot 4 \\
(3.2) \\
3670 \\
(410) \\
-\end{array}$ & $\begin{array}{c}- \\
186 \\
(16) \\
87 \\
(8) \\
121 \\
(10) \\
28 \\
(10) \\
114 \\
(9) \\
7 \cdot 7 \\
(1 \cdot 4) \\
70 \\
(15) \\
16 \\
(2) \\
15 \cdot 7 \\
(4 \cdot 1) \\
4220 \\
(370) \\
-\end{array}$ & $\begin{array}{c}- \\
190 \\
190 \\
(19) \\
90 \\
(12) \\
126 \\
(15) \\
35 \\
(15) \\
136 \\
(12) \\
8 \cdot 6 \\
(1 \cdot 8) \\
66 \\
(18) \\
15 \\
(2) \\
18 \cdot 6 \\
(5 \cdot 3) \\
4770 \\
(810) \\
135 \\
(23)\end{array}$ & $\begin{array}{c}49 \\
(15) \\
125 \\
(13) \\
71 \\
(6) \\
90 \\
(10) \\
17 \\
(4) \\
88 \\
(12) \\
4 \cdot 1 \\
(0.9) \\
52 \\
(16) \\
23 \\
(4) \\
6.0 \\
(1.8) \\
2230 \\
(330) \\
(-)\end{array}$ & $\begin{array}{c}47 \\
(12) \\
149 \dagger \\
(16) \\
78 \dagger \\
(7) \\
104+ \\
(8) \\
21 \\
(4) \\
102 \\
(11) \\
6 \cdot 3 \dagger \\
(1 \cdot 1) \\
63 \dagger \\
(14) \\
17 \\
(5) \\
11 \cdot 1 \dagger \\
(2 \cdot 7) \\
3230 \dagger \\
(490) \\
(-\end{array}$ & $\begin{array}{c}46 \\
(10) \\
160 \dagger \\
(16) \\
78 \dagger \\
(7) \\
107 \dagger \\
(12) \\
23+ \\
(5) \\
116 \\
(10) \\
7 \cdot 3 \\
(1 \cdot 7) \\
65 \\
(20) \\
16 \\
(2) \\
13 \cdot 3 \\
(4 \cdot 2) \\
3610 \dagger \\
(500) \\
-\end{array}$ & $\begin{array}{c}45 \\
(13) \\
170+ \\
(16) \\
84+ \\
(9) \\
115 \dagger \\
(13) \\
26 \dagger \\
(7) \\
137 \\
(11) \\
8 \cdot 0 \\
(1 \cdot 5) \\
61 \\
(16) \\
14 \\
(2) \\
15 \cdot 3 \dagger \\
(4 \cdot 4) \\
4140 \dagger \\
(730) \\
128 \\
(15)\end{array}$ \\
\hline
\end{tabular}

Standard deviations in parentheses.

$\star$ Seven patients only.

t Statistically significant change $(p=$ or $<0.05)$, using Student's t test to determine the significance of the observed difference from zero. 

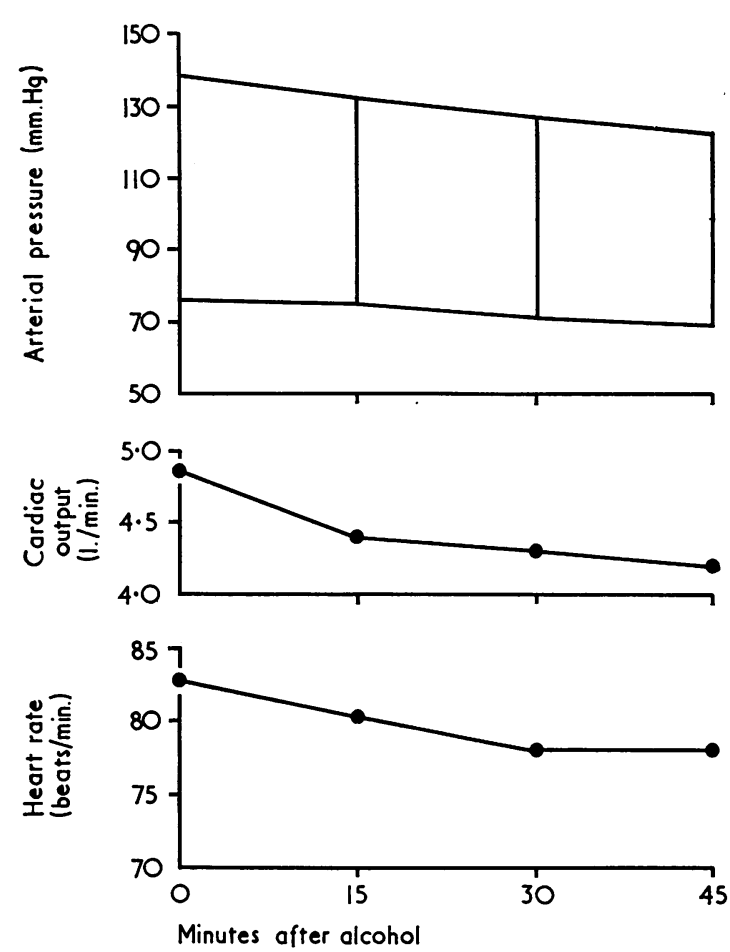

FIG. 2.-Arterial pressure, cardiac output, and heart rate at rest after alcohol.

when angina began both before and after alcohol. In 4 cases slightly more work was required after alcohol to produce angina, but the difference was not significant.

(D) Urine Volumes

Urine was collected from 6 subjects. Large
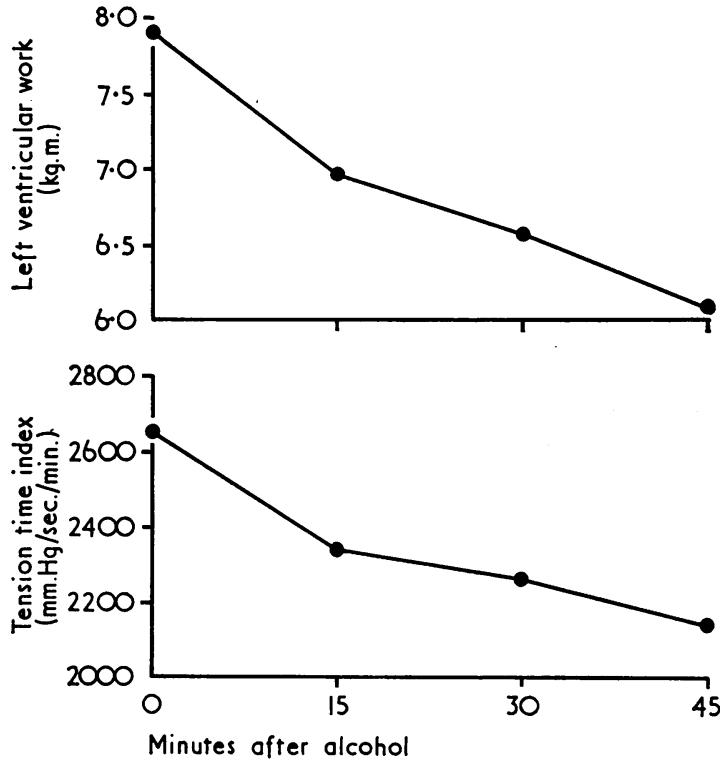

FIG. 3.-Left ventricular work and tension time index at rest after alcohol.

diureses did not occur, volumes ranging from 183 to $630 \mathrm{ml}$. (mean $353 \mathrm{ml}$.). The patient with the greatest fall in arterial pressure did not have his urine collected.

\section{Discussion}

These results show that significant haemodynamic effects were produced by moderate amounts of alcohol in patients with coronary heart disease. Absorption of alcohol was uneven, and in most cases only modest blood levels were attained so that no correlation emerged between the height of blood

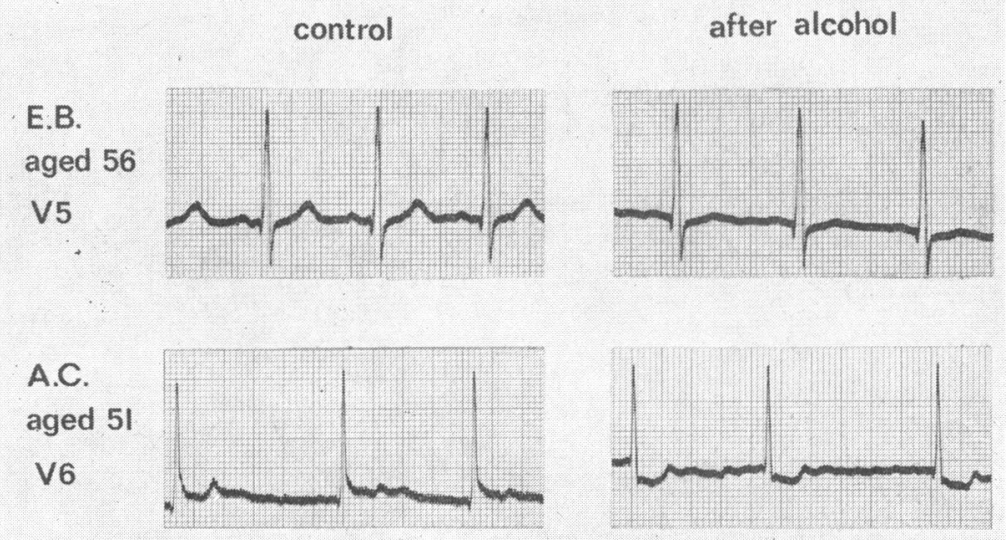

FIG. 4. - Changes in the electrocardiogram at rest, before and after alcohol. E.B. aged 56 years, lead V5. A.C. aged 51 years, lead V6. 
TABLE III

TOTAL WORK DONE UNTIL THE ONSET OF ANGINA BEFORE AND AFTER ALCOHOL (kp.m.)

\begin{tabular}{c|c|c|c|c|c}
\hline Patient & T.R. & E.B. & L.W. & P.G. & W.V. \\
\hline Before alcohol & 4650 & 3050 & 4600 & 3500 & 3300 \\
After alcohol & 2040 & 4100 & $\mathbf{4 6 7 5}$ & 3805 & 5250 \\
\hline
\end{tabular}
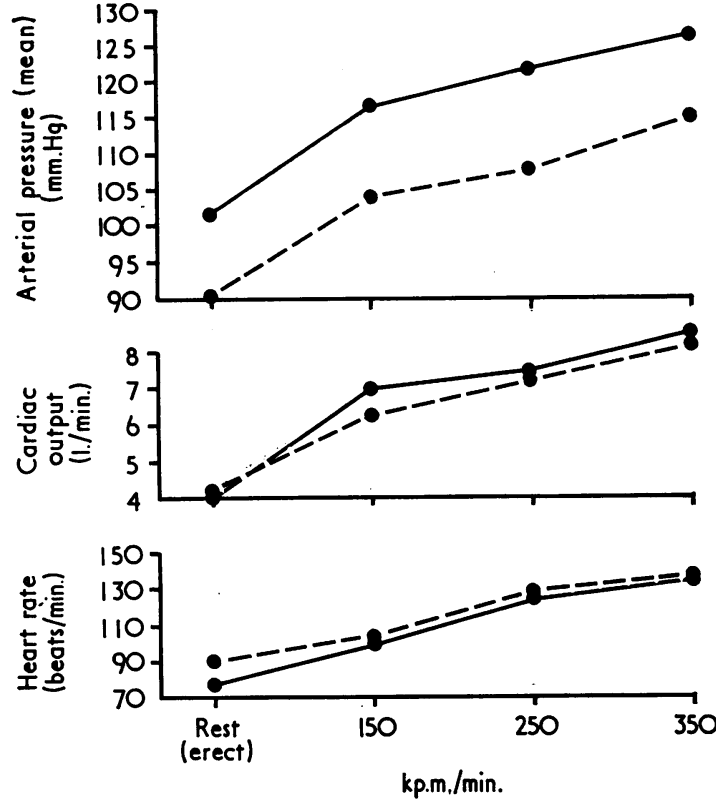

Fig. 5.-Arterial pressure, cardiac output, and heart rate at rest and during exercise, before $(\bullet-\bullet)$ and after $(\bullet-.-\bullet)$ alcohol and the degree of circulatory change. Arterial pressure dropped at rest and on effort. This reduction was paralleled by a fall in cardiac output, particularly at rest, and, therefore, there was no alteration in peripheral resistance. This is contrary to the popular conception of alcohol as a peripheral vasodilator, but it has been shown recently (Gillespie, 1967) that its reputation in this respect depends principally on an increase in skin flow (and this with healthy arteries only); muscle flow in the limbs is always reduced. Although after alcohol tachycardia might have been expected because of excitement or euphoria, in fact the heart rate did not alter. Left ventricular work declined and tension time index, reflecting myocardial oxygen consumption (Sarnoff et al., 1958), fell.

At first sight these changes appear to be beneficial but the deterioration seen in the electrocardiogram of several patients suggests that, probably, the drop in cardiac output was due to myocardial depression (with the fall in arterial pressure partly the consequence of this, and partly the result of a moderate diuresis).

Support for this hypothesis is provided by the work of Regan and his colleagues. They examined the effects of alcohol initially in dogs $(1964,1966)$
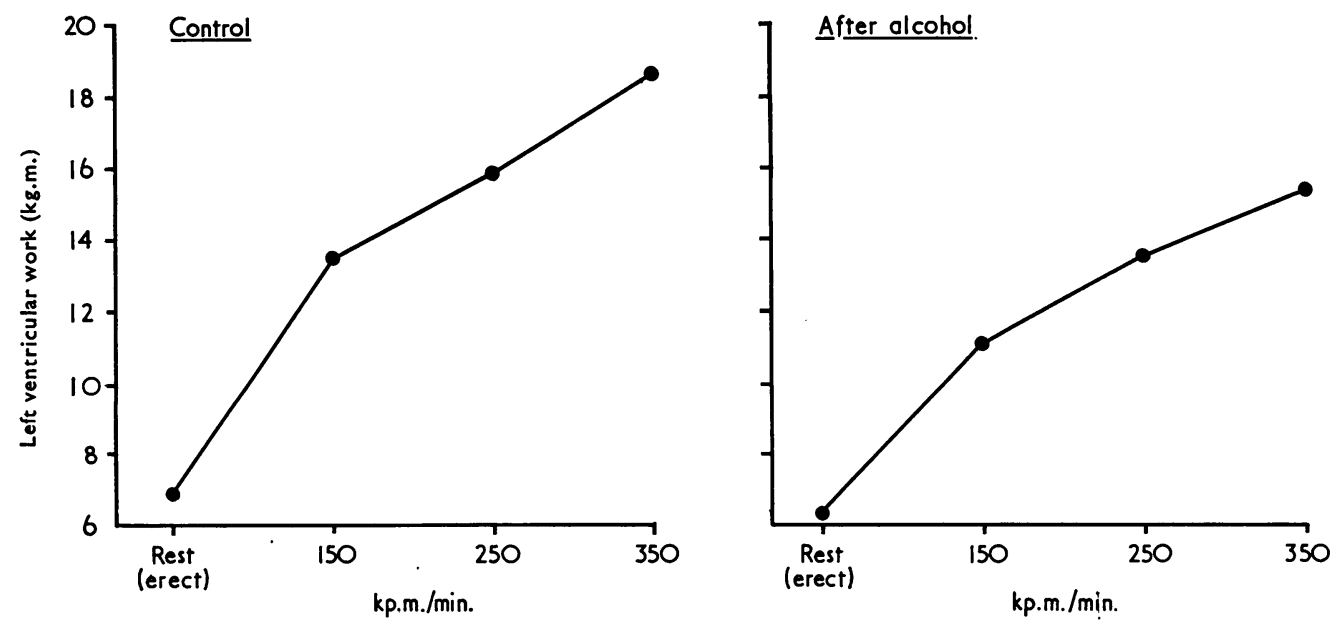

Fig. 6.-Left ventricular work at rest and during exercise, before and after alcohol. 


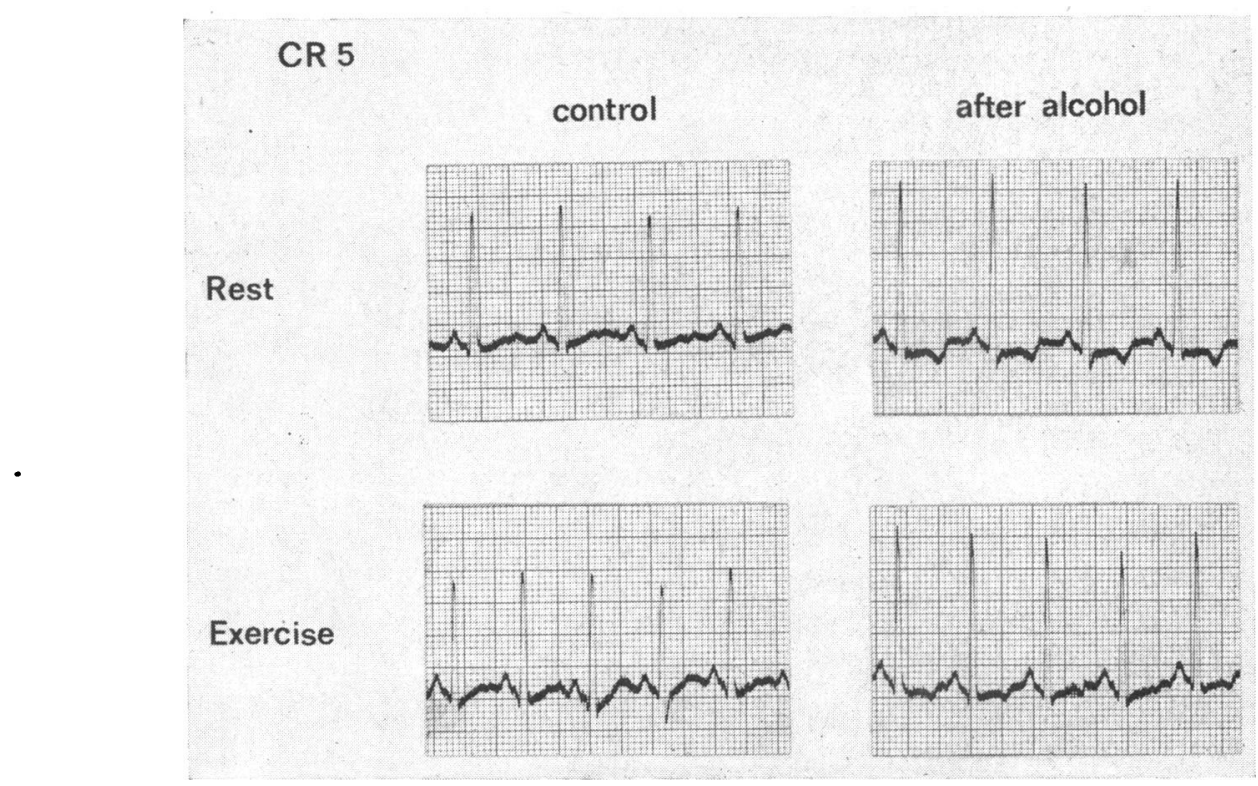

FIG. 7.-T.R. aged 61 years; lead CR5 at rest erect and during exercise.

and confirmed their findings in man (1965), studying alcoholics who were under investigation for fatty infiltration of the liver but who had normal hearts. Using larger amounts of alcohol than in the present study (110 g. taken over 2 hours), they showed that it reduced myocardial contractility and caused a small rise in left ventricular end-diastolic pressure. Stroke volume fell but the heart rate did not change. In dogs arterial pressure remained unaltered: no observations were recorded in their human subjects. Coronary sinus outflow varied very little but its content of potassium and phosphate ions and of transaminase rose. They did not comment on the electrocardiogram. These changes persisted for some hours while blood alcohol levels remained high, and they concluded that alcohol had caused reversible myocardial injury. In response to angiotensin infusion, another group of subjects, aged 30-41 years, also alcoholics and again having clinically normal hearts and normal electrocardiograms, behaved, after alcohol, as if they had heart disease. Increments in left ventricular end-diastolic pressure failed to augment stroke volume which remained static or, in most cases, decreased.

It is possible, of course, that these patients all had subclinical cardiomyopathic involvement, but the over-all conclusion of Regan and his colleagues, that alcohol causes reversible myocardial damage, is difficult to refute. These workers have, furthermore, indicated the probable mechanism. In animals they were able to reproduce their findings exactly by infusing hypertonic sucrose in concentrations sufficient to raise the plasma osmolarity by the same amount as alcohol had done, with temporary expansion of the plasma volume. Similarly, in man, the alterations in the coronary sinus blood seen after alcohol also followed sucrose infusions. Other studies on the influence of osmolarity on cat papillary muscle (Koch-Weser, 1963) and of alcohol on the contractility of the isolated rat atrium (Gimeno, Gimeno, and Webb, 1962) support their contention that alcohol acts directly upon cardiac muscle by virtue of the increase in plasma osmolarity it produces and that transient depression of myocardial function is the result.

The prime importance of these findings is in relation to the aetiology of alcoholic cardiomyopathy, but they, and those of the present study, suggest that alcohol should be taken with caution by patients with coronary heart disease.

\section{SUMMARY}

The haemodynamic effects of ethyl alcohol were investigated in 8 patients with coronary heart disease. Cardiac output and arterial pressure fell but heart rate did not change. Left ventricular work and tension time index declined. Deterioration was seen in the electrocardiograms of several patients. Ethyl alcohol is a myocardial depressant.

It is a pleasure to record my gratitude to Dr. Edgar Sowton for his ready encouragement and advice and for 
allowing me to study patients under his care. I am indebted to $\mathrm{Mr}$. John Norman and to his assistants, Miss Sheila King, Mrs. Cynthia Singh, Miss Linda Parker, and Miss Jill Faulkner for their very able and willing technical help.

\section{REFERENCES}

Conway, E. J. (1957). Microdiffusion Analysis and Volumetric Error, 4th ed. Crosby Lockwood, London.

Degerli, I. U., and Webb, W. R. (1963). Alcohol, cardiac function, and coronary flow. Surg. Forum, 14, 252.

Ganz, V. (1963). The acute effect of alcohol on the circulation and on the oxygen metabolism of the heart. Amer. Heart F., 66, 494.

Gillespie, J. A. (1967). Vasodilator properties of alcohol. Brit. med. $\mathcal{F} ., 2,274$.

Gimeno, A. L., Gimeno, M. F., and Webb, J. L. (1962). Effects of ethanol on cellular membrane potentials and contractility of isolated rat atrium. Amer. F. Physiol., 203, 194.

Holmgren, A., and Mattsson, K. H. (1954). A new ergometer with constant work load at varying pedalling rate. Scand. F. clin. Lab. Invest., 6, 137.

Koch-Weser, J. (1963). Influence of osmolarity of perfusate on contractility of mammalian myocardium. Amer. $\mathcal{F}$. Physiol., 204, 957.

Lasker, N., Sherrod, T. R., and Killam, K. F. (1955). Alcohol and the coronary circulation of the dog. F. Pharmacol. exp. Ther., 113, 414.
Leighninger, D. S., Rueger, R., and Beck, C. S. (1961). Effect of pentaerythritol tetranitrate, amyl nitrite and alcohol on arterial blood supply to ischemic myocardium. Amer. F. Cardiol., 7, 533.

Moss, L. K., Chenault, O. W., and Gaston, E. A. (1959). The effects of alcohol ingestion on experimental hemorrhagic shock. Surg. Forum, 10, 390.

Regan, T. J., Koroxenidis, G., Moschos; C. B., Oldewurtel, H. A., Lehan, P. H., and Hellems, H. K. (1966). The acute metabolic and hemodynamic responses of the left ventricle to ethanol. $\mathcal{f}$. clin. Invest., 45, 270.

—, Weisse, A. B., Moschos, C. B., Lesniak, L. J., Nadimi, M., and Hellems, H. K. (1965). The myocardial effects of acute and chronic usage of ethanol in man. Trans. Ass. Amer. Physcns, 78, 282.

- , Oldewurtel, H. A., and Hellems, H. K. (1964). The hyperosmotic effects of ethanol and sucrose on the left ventricle. F. clin. Invest., 43, 1289.

Russek, H. I., Naegele, C. F., and Regan, F. D. (1950). 'Alcohol in the treatment of angina pectoris. $\mathcal{f}$. Amer. med. Ass., 143, 355.

—, Zohman, B. L., and Dorset, V. J. (1955). Objective evaluation of coronary vasodilator drugs. Amer. $\mathcal{F}$. med. Sci., 229, 46.

Sarnoff, S. J., Braunwald, E., Welch, G. H., Jr., Case, R. B., Stainsby, W. N., and Macruz, R. (1958). Haemodynamic determinants of oxygen consumption of the heart with special reference to the tension-time index. Amer. F. Physiol., 192, 148.

Willard, P. W., and Horvath, S. M. (1964). Coronary circulation during and following ethyl alcohol infusion. Arch. int. Pharmacodyn., 148, 181. 